PPPL-2346

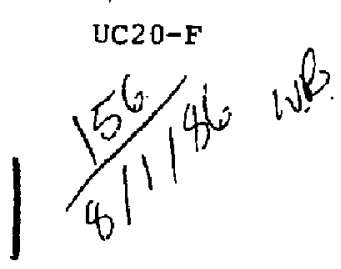

NEUTRON AND HARD X-RAY MEASUREMENTS DURING PELIET DEPOSITION IN TFTR

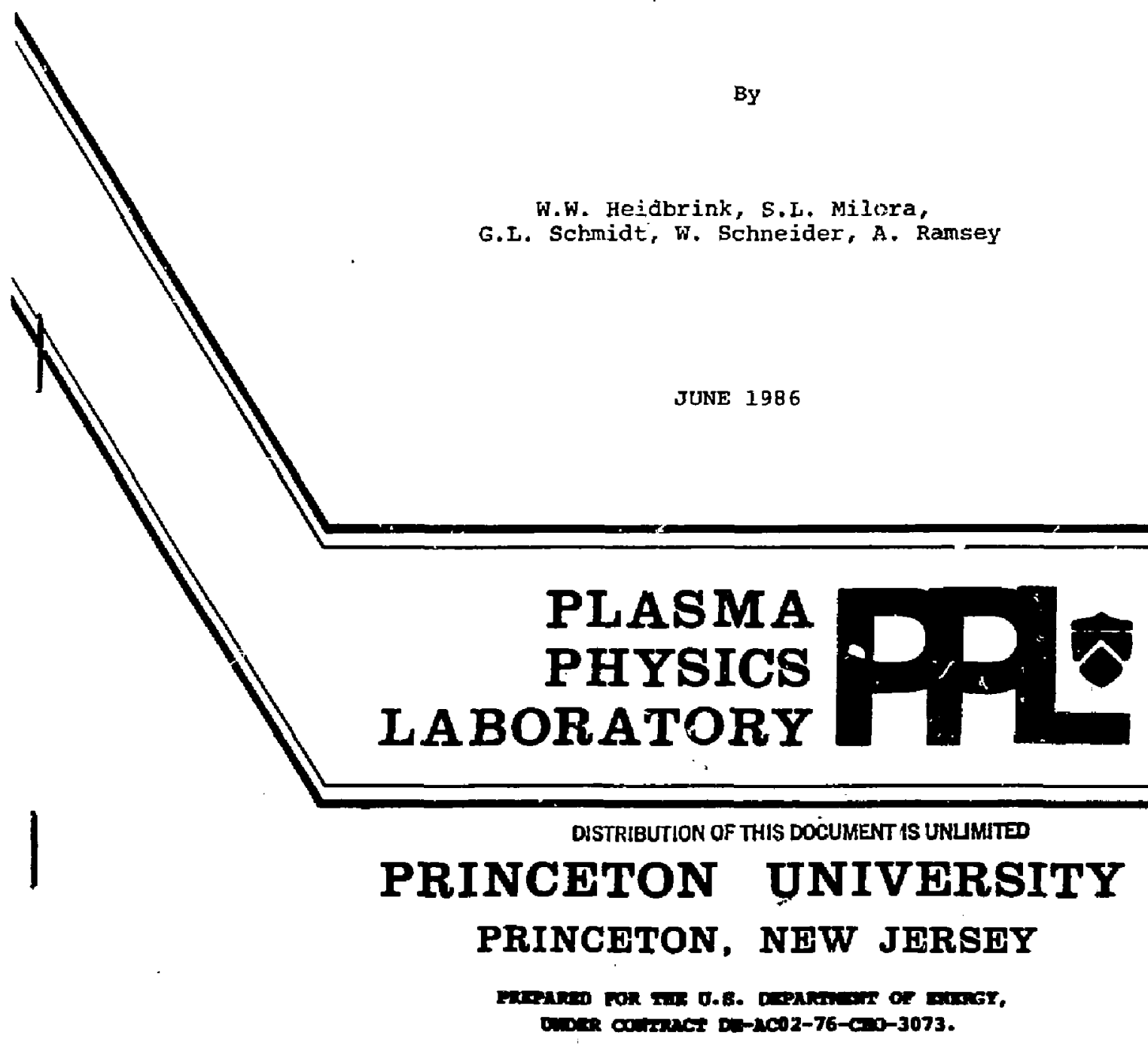


This report was prepared as an accolant of work sponsored by the United States Government. Neicher the Inited States nor the United States Department of Bnergy, nor any of their enployees, nor any of their contractors, subcontractors, or their employees, makes any warranty, exprese or inplied, or assumes any Iegal liability or responsibility for the accuracy. conpleteness or useful.nesg of any information, apparatus, product or process disclosed, or represents that 1 ts use would not infringe privately owned rights.

Pxinted in the Inlted States of America

Avallable from:

National Technical Information Service

v.S. Department of Connerce 5285 Port Royal Road

Springfield, Virginia 22161

Price Printed Copy $\$$, Microflche $\$ 4.50$

-Pagea

$1-25$

25-50

$51-75$

75-100

$101-125$

$126-150$

151-175

$176-200$

201-225

226-250

251-275

276-300

301-325

$326-350$

351-375

$376-400$

$401-425$

426-450

$45 \uparrow-475$

$476-500$

500-525

526-550

$551-575$

567-600

NTIS

selilng Price

$\$ 7.00$

\$8. 50

$\$ 10.00$

$\$ 11.50$

$\$ 13.00$

$\$ 14.50$

$\$ 16.00$

$\$ 77.50$

$\$ 19.00$

$\$ 20.50$

$\$ 22.00$

$\$ 23.50$

$\$ 25.00$

$\$ 26.50$

$\$ 28.00$

$\$ 29.50$

$\$ 31.00$

$\$ 32.50$

$\$ 34.00$

$\$ 35.50$

$\$ 37.00$

$\$ 38.50$

$\$ 40.00$

$\$ 41.50$
For documents over 600 pages, add $\$ 1.50$ for each additional 25-page increnent. 


\title{
NEUTRON AND HARD X-RAY MEASUREMENTS DURING PELLET DEPOSITION IN TFTR
}

\author{
W.W. HEIDBRINK, S.L. MLORA, ${ }^{*}$ \\ G.l. SCHMIDT, W. SCHNEIDER, ${ }^{\text {** }}$ A. RAMSEY \\ Plasma Physics Laboratory, Princeton University \\ Princeton, New Jersey USA
}

\begin{abstract}
Measurements of neutrons and hard $\mathrm{X}$ rays are made with a pair of plastic scintillators during injection of deuterium pellets into deuterium TFTR plasmas. Three cases are investigated. During ohmic heating in plasmas with few runaway electrons, the neutron emission does not increase when a pellet is injected, indicating that strong acceleration of the pellet ions does not occur. In ohmic plasmas with low but detectable levels of runaway electrons, an X-ray burst is observed on a detector near the pellet injector as the pellet ablates, while a detector displaced $126^{\circ}$ toroidally from the injector does not measure a synchronous burst. Reduced pellet penetration correlates with the presence of $\mathrm{X}$-ray emission, suggesting that the origin of the burst is bremsstrahlung from runaway electrons that strike the solid pellet. In deuterium beam-heated discharges, an increase in the $d-d$ neutron emission is observed when the pellet ablates. In this case, the increase is due to fusion reactions between beam ions and the high density neutral and plasma cloud produced by ablation of the pellet; this localized density perturbation equilibrates in about $700 \mu \mathrm{sec}$. Analysis of the data indicates that the density propagates without forming a sharp shock front with a rapid initial prepagation velocity $\left(\gtrsim 2 \times 10^{7} \mathrm{~cm} / \mathrm{sec}\right)$ that subsequently decieases to around $3 \times 10^{6} \mathrm{~cm} / \mathrm{sec}$. Modelling suggests that the electron heat flux into the pellet cloud is much less then the classical Spitzer value.
\end{abstract}

* Oak Ridge National Laboratory, USA

* Max-Planck-Institut für Plasmaphysik, FRG, EURATOM ASS.

1 OISTRBBUTION OF THIS DOCUMENT IS UNLIMITEO 


\section{INTRODUCTION}

Injection of solid hydrogenic pellets is an attractive means of fuelling a magnetic fusion reactor. The feasibility of depositing fuel deep within the plasma depends on the rate of pellet ablation which, in turn, influences the technological requirements for future pellet injectors. It is of interest, therefore, to study the interaction of the pellet mass with the plasma during and immediately following the ablation phase.

Most previous experimental studies during pellet deposition in tokamaks have relied on optical measurements. The rate of pellet ablation is inferred from the time evolution of the $\mathrm{H}_{\alpha}$ light produced by the pellet neutral cloud [1,2], photographs of the light give the pellet cloud trajectory and size [3], and spectral measurements of the light give estimates of the electron density and temperature in the pellet cloud [4]. The electron density surrounding the pellet. also has been measured using holography [5]. Fast electron cyclotron emission (ECE) and soft X-ray measurements have been used to study the effect of pellets on the electron temperature [6] and ion density [7]. The toroidal propagation of densily away from the pellet was determined using microwave interferometry and found to be $2 \times 10^{6} \mathrm{~cm} / \mathrm{sec}$ $[3,8]$.

In this paper, fast time-response measurements of neutrons and hard $X$ rays produced during deuterium pellet injection into the Tokamak Fusion Test Reactor (TFTR) are reported. After a description of the diagnostics (Sec. 2), the neutron measurements in ohmically heated plasmas are described and compared with the predictions of the Energy Transduction theory [9] of pellet ablation (Sec. 3). Next, the effect of runaway electrons on pellet penetration is studied using hard $\mathrm{X}$-ray measurements (Sec. 4). Finally, measurements of the neutron emission in neutral beam-heated plasmas are used to infer the velocity of propagation of the pellet ions away from the site of ablation (Sec. 5). The conclusions are then summarized (Sec. 6).

\section{EXPERIMENT}

For these experinents, a plastic scintillator was mounted beside the pellet injector [10] on the ridplane of TFTR, just outside the vacuum vessel, midway between the toroidal field coils (Fig. 1). A similar detector was situated $126^{\circ}$ toroidally away from the pellet injector. Because of the inverse square dependence of the neutron flux on distance, the uncollimated detectors were most sensitive to neutrons produced near the detector. In addition, some effective collimation was provided by the toroidal field coils and other massive components of the tokamak. The frequency response of these detectors was limited by the digitizer sampling ratc, which was $20 \mathrm{kHz}$. Also digitized with the scintillator signal 
was the signal from an $\mathrm{H}_{\alpha}$ detector that monitored light emitted during pellet ablation that reflected off the inner wall. In order to discriminate between hard $X$ rays and neutrons, $a$ $\mathrm{ZnS}\left({ }^{6} \mathrm{Li}\right)$ scintillator $\left(\mathrm{ZnS}\left({ }^{6} \mathrm{Li}\right)\right.$ is $\sim 30$ times less sensitive to hard $\mathrm{X}$ rays than plastic [11]) was mounted beside one of the plastic scintillators. Since the scintillators view the plasma from outside the 1.3-cm-thick stainless steel vacuum vessel, when $X$ rays are detected they generally have energies $\gtrsim 1 \mathrm{MeV}$.

After the pellet injector was installed in 1985, TFTR was operated for a relatively short time before shutting down for major renovations [12]. The observations described below are consistent with all of the available data but some of the phenomena described (Figs. 3 and 4) represent unusual TFTR operating conditions and were only observed a few times during this run period.

\section{OHMIC NEUTRON EMISSION}

In ohmically heated plasmas $\left(I_{p}=1.4-2.2 \mathrm{MA} ; \bar{n}_{e}=3-8 \times 10^{13} \mathrm{~cm}^{-3} ; T_{c}(0)=\right.$ 1-3 keV) with relatively few runaway electrons (no detectable $X$-ray enhancement of the plastic scintillator signal), an increase in neution emission at the time of pellet injection has not heen observed in any of the $\sim 100$ cases archived on TFTR. Typically, $2.7-m m-$ diameter pellets penetrated to within $25 \mathrm{~cm}$ of the magnetic axis $(a=81 \mathrm{~cm})$ in these plasmas and 4.0-mm pellets appeared to pass completely through the plasma without fully ablating. In the inner third of the plasma (where most of the neutron emission originates), the density increased by as much as $270 \%$ upon pellet injection. Typical data are shown in Fig. 2. Within the neution experimental accuracy, which is about $\pm 10 \%$ at this emission level, the neutron yield falls monotonically ir about $8 \mathrm{~ms}$ to a reduced level (as the ion temperature falls due to the influx of cold particles), then gradually recovers (Fig. 2a). The neutron exponential decay time shortly after injection (when the pellet density has spread over the flux surfaces) is about $1 \mathrm{~ms}$, which is consistent with the time required for the jons that produce most of the fusion reactions $\left(E \sim 5 T_{i}\right.$ ) to slow down due to Coulomb drag ( $\tau_{*} \simeq 3 \mathrm{~ms}$ ). Analysis of the equation for the neutron yield indicates that, for thermonuclear emission (assuming the pellet ions are initially cold), the expected increase in neutron yjeld just after the pellet density has spread over the flux surface is $\$ 5 \%[13]$, in agreement with experiment.

Mayer [9] has predicted that ions should be accelerated by the ablation process to energies $E$ of $E \simeq 9 T_{e}$, where $T_{e}$ is the electron temperature prior to pellet injection. If such acceleration occurred, it would produce a large increase in neutron yield since the $d(d, n)$ fusion cross section is a very strong function of energy. Calculations of the fusion: 
reactivity of a monoenergetic beam of ablated ions at $E=9 T_{i}$ in a Maxwellian plasma of ion temperature $T_{i}=2 \mathrm{keV}\left(T_{i}<T_{e}\right.$ before pellet injection) indicate that the neutron emission would increase about sixty times if such acceleration occurred. The observed increase implies that the actual ion acceleration for a typical ion must be less than about $0.5 T_{\text {e }}$. Epithermal neutron measurements on Doublet III also are inconsistent with strong ion acceleration $[14]$.

\section{OHMIC X-RAY EMISSION}

In ohmically heated discharges with higher levels of runaway electrons, the signais from the plastic scintillators are dominated by hard $\mathrm{X}$ rays rather than by neutrons. Operationally, the level of runaway electrons in these plasmas, though higher than in the discharges discussed in Sec. 3, remains much lower than in "runaway discharges" and there is no obvious evidence from other diagnostics (e.g., the loop voltage or ECE) of a large zunaway electron population. When a pellet is injected into one of these discharges, a large spike in the $\mathrm{X}$-ray emission occurs on the detector beside the pellet injector (Fig. $3 \mathrm{a}$ ). The burst of hard $\mathrm{X}$ rays slightly precedes the peak in $\mathrm{H}_{\alpha}$ emission; on the toroidally displaced scintillator, a smaller jump in X-ray emission occurs after the pellet has begun to ablate (Fig. 3b). For this shot, the $\mathrm{X}$-ray emission fell shortly after injection to about half its initial level.

The observed signals are consistent with the interpretation that the hard X-ray spike is bremsstrahlung produced in collisions between runaway electrons and the solid or ablated pellet mass. Neither scinitillator was situated to observe high-energy X rays produced when runaways strike the limiter (Fig. 1). Runaway electrons are about equally likely to produce high-energy $\mathrm{X}$ rays whether the pellet is frozen or ablated. The range of $1 \mathrm{MeV}$ electrons in solid deuterium is about $23 \mathrm{~mm}$ [15], so the 3-4 $\mathrm{mm}$ solid pellets seem thin to runaways. This implies that the X-ray yield $I_{x}$ is roughly independent of the state of the peilet atoms since

$$
I_{x} \propto \int n_{r} n_{p} d r \simeq n_{r} \int n_{p} d r=n_{r} N_{p}
$$

where $n_{r}$ is the density of runaways with energy $\gtrsim 1 \mathrm{MeV}$ and $N_{p}$ is the total number of pellet ions. Thus, it is possible for the X-ray signal to peak before the $\mathrm{H}_{\alpha}$ trace (Fig. $3 \mathrm{~b}$ ).

Several factors affect the relative size of the $\mathrm{X}$-ray spike. One factor is the highly anisotropic character of the $\mathrm{X}$-ray emission. For our experiments, the scintillator was situated in the forward cone of the $X$-ray emission (Fig. 1), which enhances the signal level relative to uniform emission. Because the $X$ rays are at:tenuated by the vacuum vessel 
and their spectrum is not well known, it is difficult to evaluate precisely the magnitude of this enhancement. Estimates indicate that the signal could be enhanced by a factor of four to twenty. A second factor reduces the magnitude of the $\mathrm{X}$-ray burst compared to the background level. In the plasma, runaways are more likely to produce $\mathrm{X}$ rays in collisions with high $Z$ impurities than in collisions with deuterons: since bremsstrahlung is proportional to $Z^{2}$, the burst from a $Z=1$ pellet should be roughly $\Delta I_{x} / I_{x} \propto N_{p} / Z_{e f f} N_{e}$, where $N_{e}$ is the total number of plasma electrons (the runaway density profile is expected to be fairly flai). Our rough expectation is, therefore, that the spike in X-ray emission $\Delta I_{x}$ observed on the scintillator adjacent to the pellet injector should be

$$
\frac{\Delta I_{x}}{I_{z}} \sim \frac{\epsilon_{\text {point }}}{\epsilon_{q \text { coidal }}} \frac{I}{Z_{\text {eff }}} \frac{N_{p}}{N_{e}} \frac{\text { Peaking }}{\text { Isotropic }} \simeq(6)\left(\frac{1}{3.5}\right)\left(\frac{1}{2}\right)(8)=7
$$

where $\epsilon$ is the geometrical efficiency of the aetector for a point source and for a toroidally uniform source, respectively, and the parameters are for the discharge shown in Fig. 3. Experimentally, $\Delta I_{x} / I_{x}=8$ (Fig. 3) so the observation is consistent with our estimate.

The reduction in $\mathrm{X}$-ray level after injection probably is not due to deceleration of the runaways by the pellet since a typical runaway only intersects the pellet cloud once during the ablation process and loses little energy in the interaction. A more likely explanation is that, in this discharge, some runaways escaped the plasma during injection while others remained confined. In other lischarges with larger $N_{p} / N_{e}$, the $\mathrm{X}$-ray level was $30 \%$ larger after the $\mathrm{X}$-ray burst than before injection, indicating that the product of ion and runaway densities was increased by pellet injection. In a few discharges that disrupted following pellet injection, the hard X-ray level fell (without a measurable burst) to below the detectable leve! when the pellet was injected. It would appear that the absence of an X-ray burst in these unstable discharges indicates that most of the runaways were lost from the plasma before they could strike the pellet.

In the absence of zunaway electrons, large pellets (4-mm diameter) appeared to pass through the TFTR plasma without completely ablating; for injection with these pellets, the ablation tine correiates weakly with the ri-ray signal level (correlation coefficient $R^{2}=0.13$ ). For smaller pellets (2.7-mm diameter), we have few data with detectable hard $\mathrm{X}$-ray levels. (Operationaily, the presence of $\mathrm{X}$ rays was considered deleterious to deep pellet penetration and was avoided.) Nevertheless, for the two shots where small pellets were injected into plasmas with $\mathrm{X}$ rays, the presence of hard $\mathrm{X}$ rays correlates with reduced pellet penetration. For these discharges, the ablation time was $0.28 \mathrm{msec}$ (compared to $0.34 \pm 0.02$ msec on lischarges in the same sequence that did not hav: detectable $X$ rays) and $0.26 \mathrm{msec}$ (comjared to $0.31 \pm 0.03 \mathrm{msec}$ ). The observation of reduced penetration in 
plasmas with modest levels of hard X-ray emission, together with the measurement of an $\mathrm{X}$-ray burst at the time of pellet injection, provides strong support for the hypothesis [8] that runaway electrons enhance the rate of pellet ablation.

\section{E. $\mathrm{D}^{0} \rightarrow \mathrm{D}^{+}$NEUTRON EMISSION}

\subsection{Experimental Results}

During $\mathrm{D}^{0} \rightarrow \mathrm{D}^{+}$neutral beam injection, the neutron emission usually is dominated by beam-target reactions. When a pellet is injected into a plasma during beam injection, a spike in the neutron emission occurs (Fig. 4a) as the density of target ions rapidly increases. Following pellet injection, the neutron yield falis with an initial time constant of about $10 \mathrm{~ms}$ (Fig. 4a) as the beam ions slow down in the colder, more collisional, plasma. In contrast to the hard X-ray emission produced by runaway electrons (Fig. $3 \mathrm{~b}$ ), the neutron emission produced by beam ions does not peak until after pellet ablation (Fig. 4b). This difference is because, while runaways can penetrate the shielding cloud and solid pellet, beam ions do not have a significant fusion reaction probability until after the pellet density is more diffuse. After pellet ablation, the neutron flux near the pellet injector begins to fall, while the flux away from the injector rises, indicating that the density added by the pellet is redistributing toroidally (Fig. 4b). For the case shown in Fig. 4, which is for pellet injection into a relatively low density plasma $\left(\bar{n}_{\mathrm{e}}=1.1 \times 10^{13} \mathrm{~cm}^{-3}\right)$, the two signals coalesce after 0.7 msec and then decay together. When a similar pellet was injected into a higher density plasma $\left(\bar{n}_{e}=3.1 \times 10^{13} \mathrm{~cm}^{-3}\right)$, the jump in neutron yield $\Delta I_{n}$ was smaller $\left(\Delta I_{n} / I_{n}=40 \%\right)$ and the two signals coalesced approximately 0.2 msec after pellet. ablation.

\subsection{Phenomenological Analysis}

The time scale for density propagation along field lines in TFTR is much shorter than the 20-50 msec time scale observea for relaxation of the radial density profile [16]. The characteristic velocity for parallel denaity transport is the ion sound speed $c_{s}=\sqrt{T_{e} / M}$, where $T_{c}$ is the electron temperature and $M$ is the deuterium mass. For large density perturbations, the velocity of propagation can exceed the sound speed but never by more than approximately $1.6 \mathrm{c},[17]$. To analyze the neutron data (Fig. 4b), we adopt a phenomenological model in which the density propngates along field lines at the sound speed, and treat the electron temperature at the propagating front and the profile of the density behind the front as free parameters. The electron temperature is permitted to vary with 
time but the shape of the density profile is held fixe.i. In reality, the shape of the profile probably also varies but our model suffices to uncover the basic physics. The deposition of particles on a field line is assumed to be proportional to the $H_{\alpha}$ trace and particles are conserved once deposited in a flux tube. For simplicity, the electron temperature is assumed to be the same function of time along every field line but our conclusions do not depend scnsitively on this assumption. Because the diameter of the pellet cloud $d$ is small compared to the circumference of a flux surface $2 \pi r$ and since most field lines are on irrational surfaces, a typical field line is very long $[L \simeq(2 \pi r / d)(2 \pi R+q 2 \pi r)=O(1 \mathrm{~km})]$. The neutron signals are simulated by averaging the density on lines near each detector: each field line is weighted by its solid angle at the detector and by the estirnated beam-ion density on that line.

The results of the simulation indicate that the density propagation is initially rapid $\left(\sim 3 \times 10^{7} \mathrm{~cm} / \mathrm{sec}\right)$, which corresponds to an initial electron temperature of order $1 \mathrm{keV}$. The features in the data (Fig. 4b) that imply rapid initial propagation are (1) the flux at the toroidally displaced detector rises before the pellet has finished ablating, (2) the flux at the adjacent detector drops immediately after ablation, and (3) the maximum jump in flux is about twice the jump observed after density equilibration. As shown in Fig. 5a, if all of the density stayed in the vicinity of the pellet injector, a six-fold increase in signal would be observed.

After an initial phase of rapid propagation ( $\sim 0.2 \mathrm{msec}$ ), the data (Fig. $4 \mathrm{~b})$ then begin to change more slowiy, taking 0.7 msec to coalesce. As shown in Fig. $5 \mathrm{~b}$, this relatively slow coalescence inplies that the temperature near the pellet cloud must fall to $10-50 \mathrm{eV}$ (a propagation velocity of approximately $3 \times 10^{6} \mathrm{~cm} / \mathrm{sec}$ ). This is the local temperature of the propagating density prior to equilibration on the flux tubes. ECE measurements show that after density and temperature equilibration the temperature on the field lines was $\sim 1 \mathrm{keV}$.

The general character of the profile of the propagating density can be evaluated by noting another feature of the data ( $\mathrm{Fig} .4 \mathrm{~b}$ ): the abserice of oscillations. Simulations with a square density profile (Fig. $5 \mathrm{c}$ ) indicate that, if such a sharp shock front formed, large $(\sim 30 \%)$ oscillations in the neutron emission would be observed each time the density fronts passed by a detector. Realistic variations in q-profile and propagation velocity $c_{s}$ as a function of minor radius reduce the amplitude of the simulated ascillations but cannot eliminate them altogether. In order to reproduce the data, it is necessary to assume that the amplitude of the density perturbation decreases away from the site of pellet ablation. Good agreement with the data is obtained with a simulation that employs a triangle-shaped 
density function,

$$
\Delta n_{d} \propto\left\{\begin{aligned}
\frac{c_{s}}{t}\left(1-\frac{|x| t}{c_{s}}\right) & \text { if }|x| t / c_{s}<1 \\
0 & \text { otherwise, }
\end{aligned}\right.
$$

and a +ime varying propagation velocity $c_{s}(t)$ that initially corresponds to $T_{e}=3 \mathrm{keV}$ but gradually slown to a velocity corresponding to $\tau_{e}=20 \mathrm{eV}$ (Fig. $5 \mathrm{~d}$ ).

Conceivably, some of the ion lensity propagates as neutra! atoms rather than as ions along the field lines. Estimates, however, indicate that neutral propagation probaioly accounts for $\leqslant 10^{-3}$ of the ion density near the toroidally displaced detector (S2).

\subsection{Nonlocal Heat Flux Calculation}

The general features of the density propagation data are consistent with calculations of plasma transport along field lines reported by Kaufmann et al. [18]. These authors found that, due to finite heat conduction along the field line, no sharp shock front should form. Their calculations also predicted some reduction in propagation velocity due to cooling of the plasma by the pellet. To test quantitatively the predictions of this model we have calculated the average density beside the neutron detectors with the PELLET computer code [18]. Data representative of a typical field line were selected for this onedimensional calculation. Since detailed krowledge of the pellet and shielding cloud radij are unavailable, the pellet radius and field line length are essentially free parameters in the calculation, but the density propagation was found to be insensitive to changes in these parameters. When the classical spitzer-Härm expression for the electron heat flux was used to describe electron thermal conduction, the code predicted that the density equilibrates much more quickly than is observed experimentally (Fig. 6a). When the conduction was treated as a nonlocal mechanism [19] (ensuring that the electron heat flux is always smaller than the free-streaming level), the simulation was consistent with the experiment within modelling uncertainties (Fig. 6b). With the nonlocal expression for the heat flux, the electron temperature near the pellet 0.1 msec after ablation was $\sim 20 \mathrm{eV}$; with the SpitzerHärm expression, the temperature was $\sim 600 \mathrm{eV}$. With either expression for heat flux, the velocity of the leading edge of the density perturbation remained $\sim 4 \times 1.0^{7} \mathrm{~cm} / \mathrm{sec}$ throughout the propagation phase. The calculations utilizing the nonlocal expression for heat flux also successfully predicted the faster density propagation observed when a pellet was injected into a higher density plasma. We conclude that some mechanism that strongly cools field lines (such as reduceci parallel thermal conductivity) is required to explain the relatively slow propagation velocities observed in the experiment. 


\section{CONCLUSION}

Scintillator measuremems of neutrons and hard $X$ reys produced during deuterium pellet injection into :'FTR indicate ( 1 j that the strong ion scceleration predicted $b y$ Mayer

[9] is not observed experimentally, (2) that modest levels of rimaway electrons reduce pellet penetration, and ( $C$ ) that the model of cooling wong the field line described by Kaufrnan et al. [18] is in agreenent $v$ ith measirements of the propagation of the ion density away from the pellet.

\section{ACKNOWLEDGEMENTS}

We thank T. Deverell, D. Meade, K. Young, and the entire TFTR staff for assistance in performing the messurements, an 1 especially H. Park, G. Taylor, and F. Stauffer for electron density and temperature data. $\mathrm{F}_{h}$. Hendel measured the absolute magnitude of the neution emission. Helpful discussions with R. Goldston, W. Hioulberg, I. Strachan, and S. Zweben are gratefully acknowledged. This work was supported by U.S. Department of Energy Contract No. DE-ACO2-76-CHO-3073.

\section{References}

[1] FOSTER, C.A., COLCHIN, R.J., MILORA, S.ĩ., KIM, K., TURNBULL, R.J., Nucl. Fusion 17 (1977) 1967.

[2] MILORA, S.L., J. Fusicu Energy 1 (1981) 15.

[3] MILORA, S.L., FOSTER, C.A., EDMONDS, P.H., SCHMIDT, G.L., Phys. Rev. Lett. 42 (1979) 97.

i4] McNEILL, D.H., GREENE, G.J., SCHURESKO, D.D., Phys. Rev. Lett. 55 (i985) 1398.

[5] THOMAS, C.E., "An Experimental Investigation of Solid Hy drogen Pellex Ablation in High-Temperature Plasmas using Holographic Interferometry and other Diagnostics," Oak Ridge N.L. Rept. ORNL/TM-7486 (1981).

[6] GREenWALD, M., et al., Phys. Rev. Lett. 53 (1984) 352.

[7] PARKER, ¿., GREENWALD, M., PETRASSO, R.., GRANE7Z, R., GOMEZ, C. " $m=1, n=1$ Oscillations following the Injection of a Fuel Pellet on the Alcator $\mathrm{C}$ Tokamak," M.J.T. Rept. No. PFC/JA-85-36 (1985).

[8] MILORA, S.i., et al., Nucl. Fusion 20 (1980) 1491.

[9] MAYER, F.J., Phys. Rev. Lett. s5 (1985) 1673. 
[10] COMBS, S.K., MILORA, S.L., FOUST, C.R., FOSTER, C.A., SCHURESKO, D.D., Rev, Sci. Instrum. 56 (1985) 1173.

[11] HEIDBRINK, W.W., in Proc. of the $6^{\text {th }}$ Topical Conf. on Plasma Diagnostics, Rev. Sci. Instrum. 57 (1986) in press.

[12] SCHMIDT, G.L., MILORA, S.L., et al., Proc. of the $12^{\text {th }}$ European Conf. on Cont. Fusion and Plasma Physics (Budapest 1985), Vol. II, 674.

[13] HEIDBRINK, W.W., "Energetic Ion Diagnostics using Neutron Flux Measurements during Pellet Injection," Princeton Plasma Physics Lab. Rept. PPPL-2299 (1985).

[14] SCHISSEL, D.P., Phys. Rev. Lett. 56 (1986) 1310.

[15] KATZ, L., PENFOLD, A.S., Rev. Mod. Phys. 24 (1952) 28; LENGYEL, L.L., Max-Planck-Institut für Plasmaphysik Rept. IPP 1/233 (1984).

[16] PARK, H., et al., Bull. Am. Phys. Soc. 30 (1985) 1386.

[17] DAVIDSON, R.C., Methods in Nonlizear Plasma Theory, Academic Press, New York (1972) ch. 2.

[18] KAUFMANN, M., LACKNER, K, LENGXEL, L., SCHNEIDER, W., Nucl. Fusion 26 (1986) 171.

[19] LUCIANI, J.F., MORA, P., VIRMONT, J., Phys. Pev. Lett. 51 (1983) 1663. 


\section{Figure Captions}

Fig. 1 Plan view of TFTR showing the relative position of the diagnostics.

Fig. 2 (a) Neutron emission from an ohmically heated deuterium plasma. A deuterium pellet was injected at 2.10 sec. $I_{p}=2.2 M A_{;} B_{\imath}=4.8 T ; n_{e} l=6.0 \times 10^{19} \mathrm{~m}^{-2}$. The pellet penetrated approximately $60 \mathrm{~cm}$ into the $81-\mathrm{cm}$ minor radius plasma. Signal from the scintillator adjacent to the pellet injector (S1) and from the $\mathrm{H}_{\alpha}$ detector around the time of pellet injection.

Fig. 3 (a) Signal from the plastic scintillator adjacent to the pellet injector in an ohmically heated plasma with hard $X$ rays. A pellet was injected at 1.87 sec. The trace labeled "neutrons" is from the $\mathrm{ZnS}\left({ }^{6} \mathrm{Li}\right)$ scintillator. $I_{p}=2.2 M A_{;} B_{t}=4.8 T_{;} n_{e} l=$ $3.5 \times 10^{19} \mathrm{~m}^{-2}$. (b) Signal from the scintillator adjacent to the pellet injector (S1), from the toroidally displaced scintillator (52), and from the $H_{a}$ detector around the time of pellet injection. No spike was observed on the $\mathrm{ZnS}\left({ }^{6} \mathrm{Li}\right)$ scintillator.

Fig. 4 (a) Neutron emission from a deuterium beam-heated plasma. The beams were on from $2.50-3.00$ sec and a pellet was injected at $2.80 \mathrm{sec} . I_{p}=0.8 \mathrm{MA} ; B_{i}=4.0 \mathrm{~T}$; $7_{e} l=1.7 \times 10^{19} \mathrm{~m}^{-2} ; P_{b}=2.5 \mathrm{MW}$. The pellet penetrated approximately $44 \mathrm{~cm}$. Signal from the scintillator adjacent to the pellet injector $(S 1)$, from the toroidally displaced scintillator (S2), and from the $H_{\alpha}$ detector around the time of pellet injection. The absolute magnitude of the neutron yield is only valid for toroidally uniform emission.

Fig. 5 Neutron signals simulated using the model described in the text. (a) Overshoot of $S 1$ and slow rise of $S 2$ for low propagation velocity (constant propagation velocity, triangle density function). (b) Rapid coalescence of simulated signals for high propagation velocity (constant propagation velocity triangle density function). (c) Oscillating signals for sharp shock front (time varying propagation velocity, square density function). (d) Good fit to the data of Fig. 4 b (time varying propagation velocity, triangle density function).

Fig. 6 A verage density on the field line at toroidal iangles of $0^{\circ}$ and $120^{\circ}$, as calculated by the code PELLET [18] under the assumptions of (a) classical electron thermal conduction and of (b) nonlocal [19], flux-limited, thermal conduction. $T_{e}=2.75 \mathrm{keV}$; $T_{i}=4.0 \mathrm{keV} ; n_{e}=1.2 \times 10^{13} \mathrm{~cm}^{-3} ; r_{p e l}=0.35 \mathrm{~mm} ; v_{p e l}=1.4 \times 10^{5} \mathrm{~cm} / \mathrm{sec} ;$ field line length $=2.4 \mathrm{~km}$. 
\#86X0564

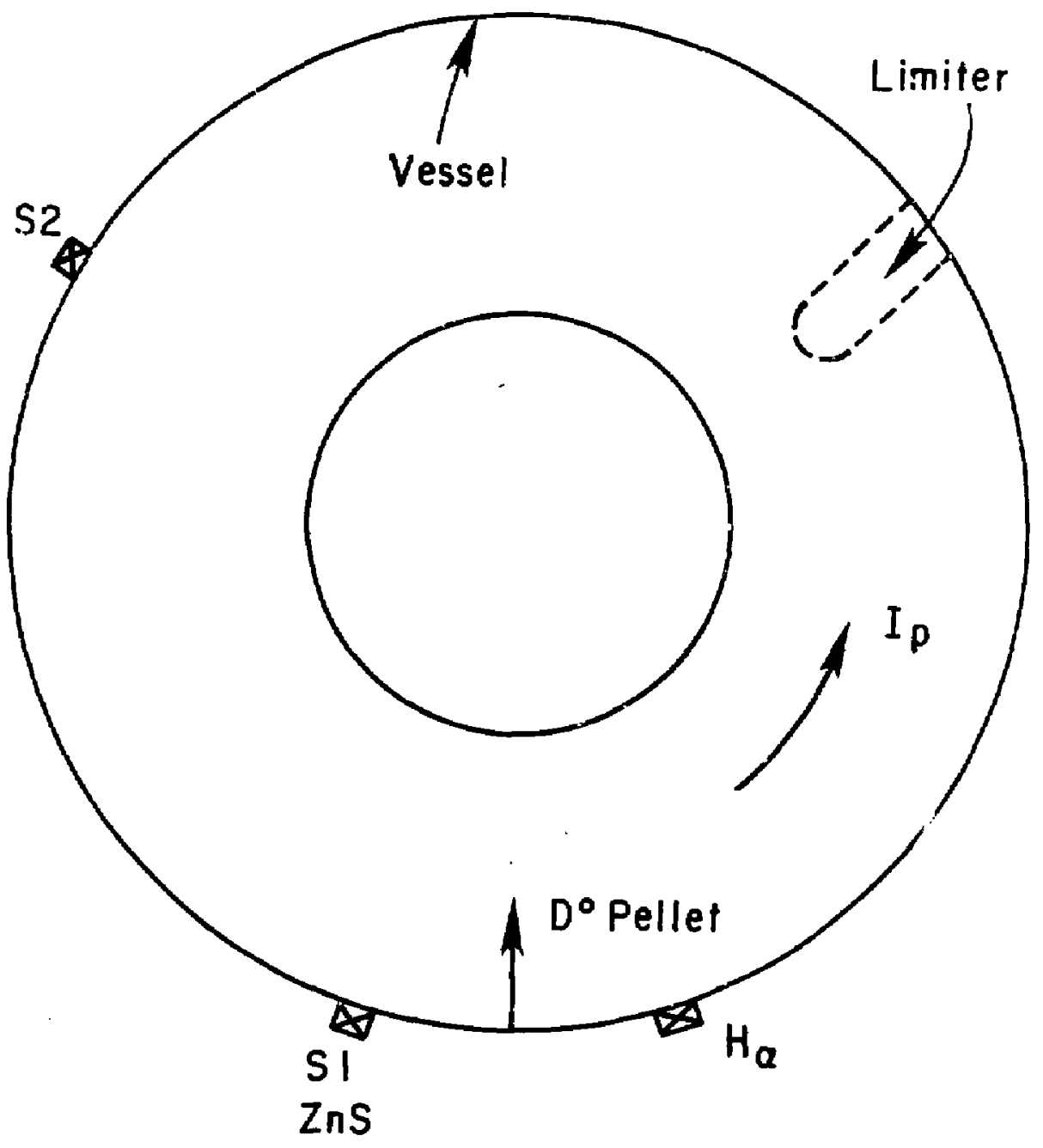

Fig. 1 


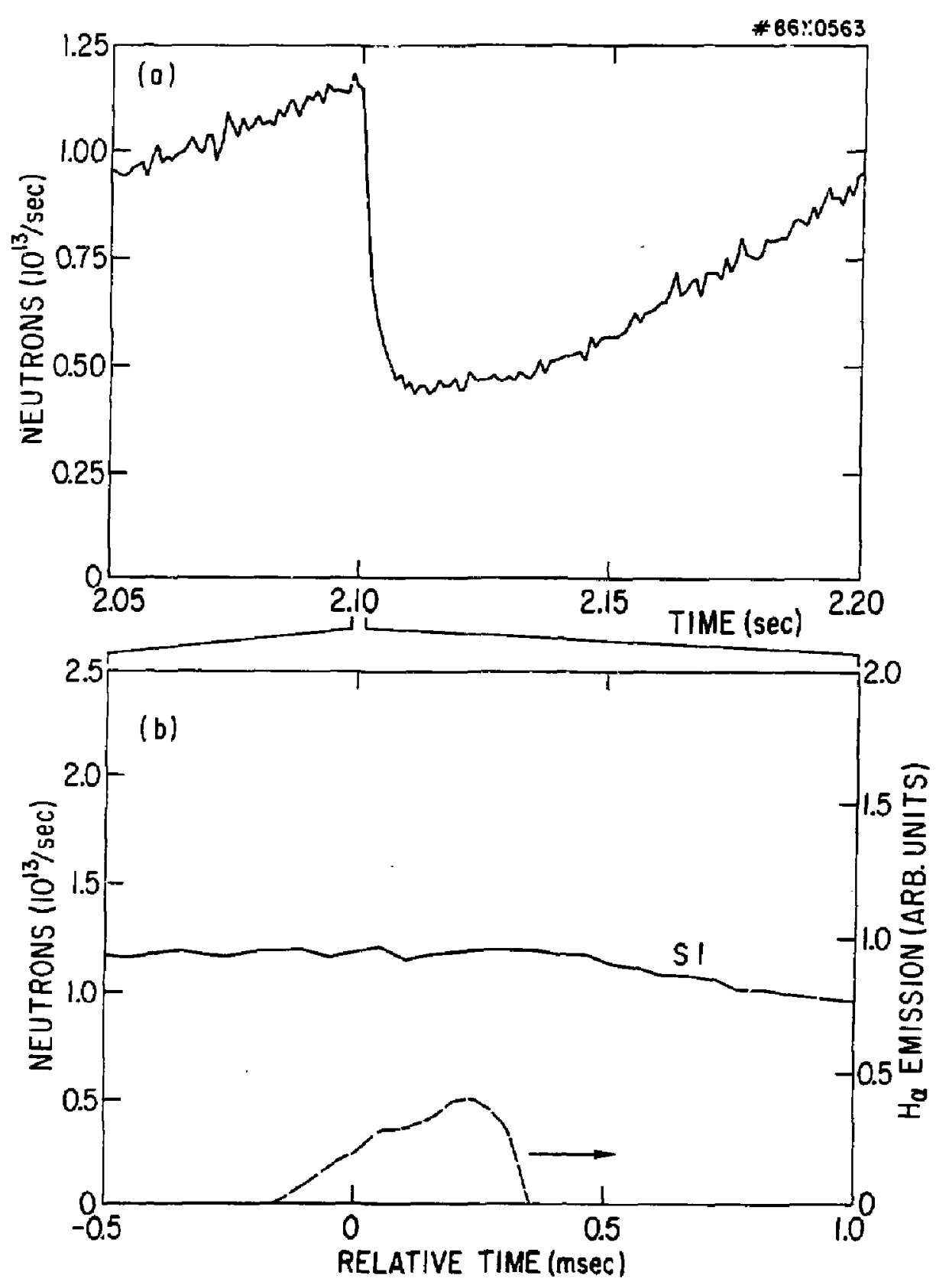

Fig. 2 

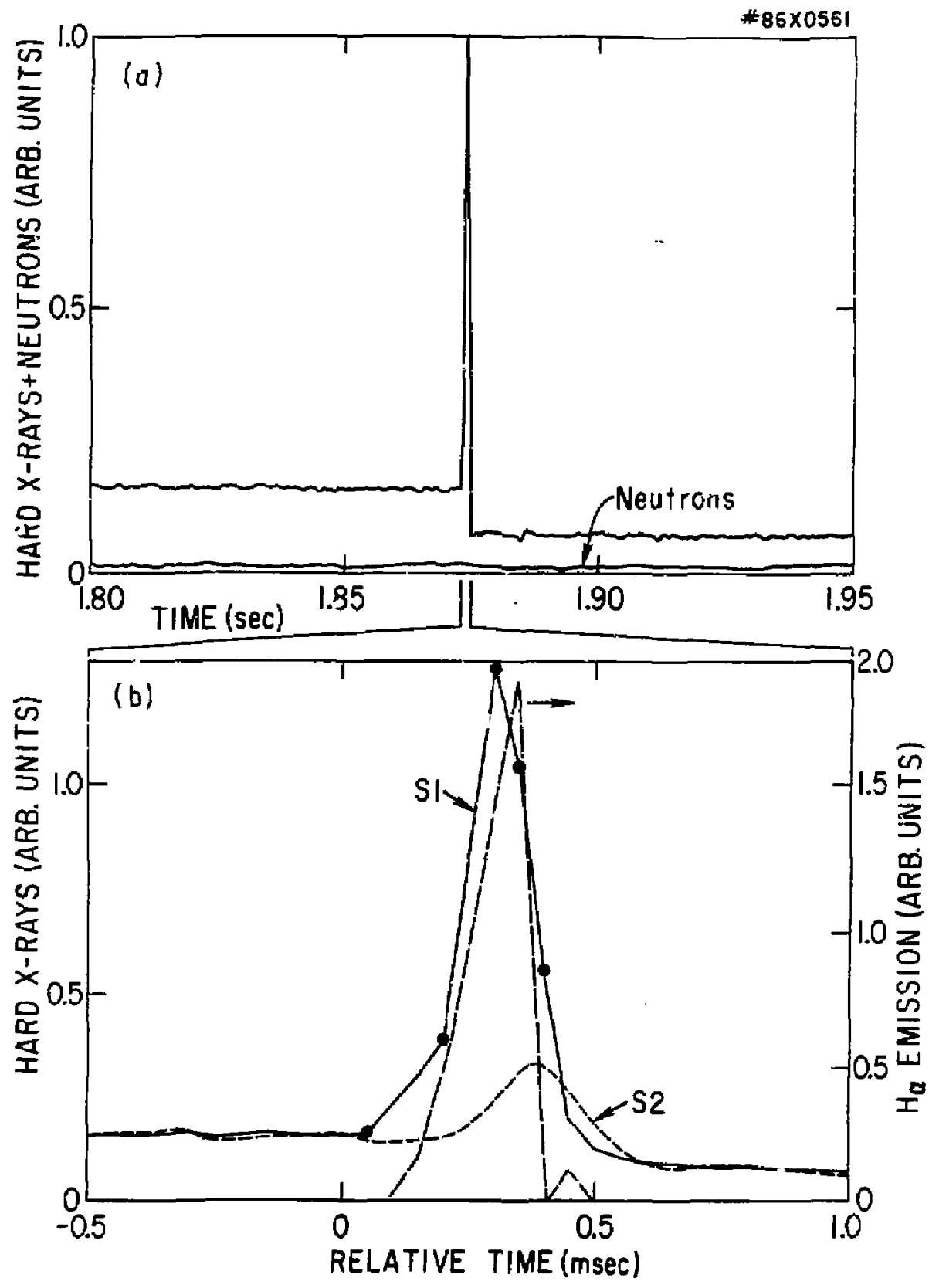

Fig. 3 


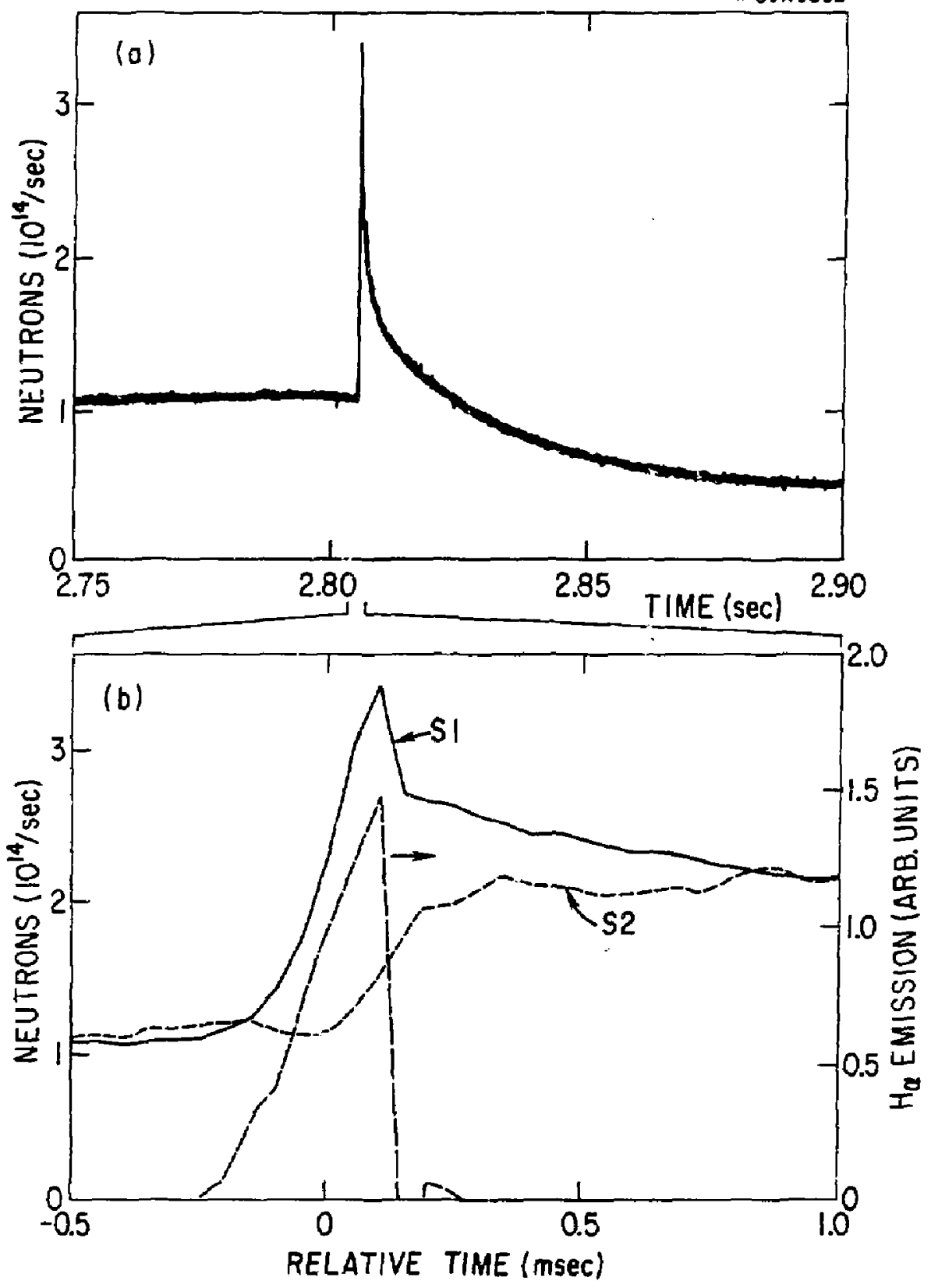

Fig. 4 


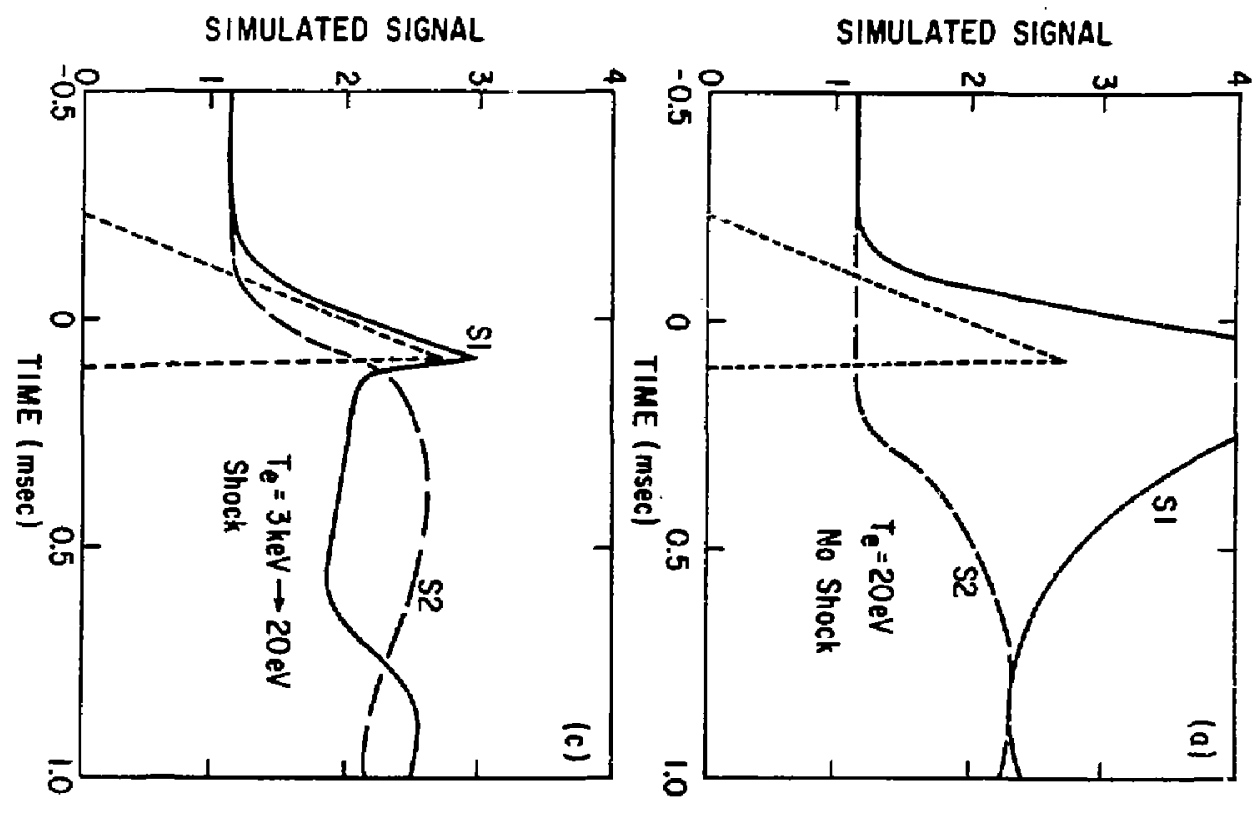

?

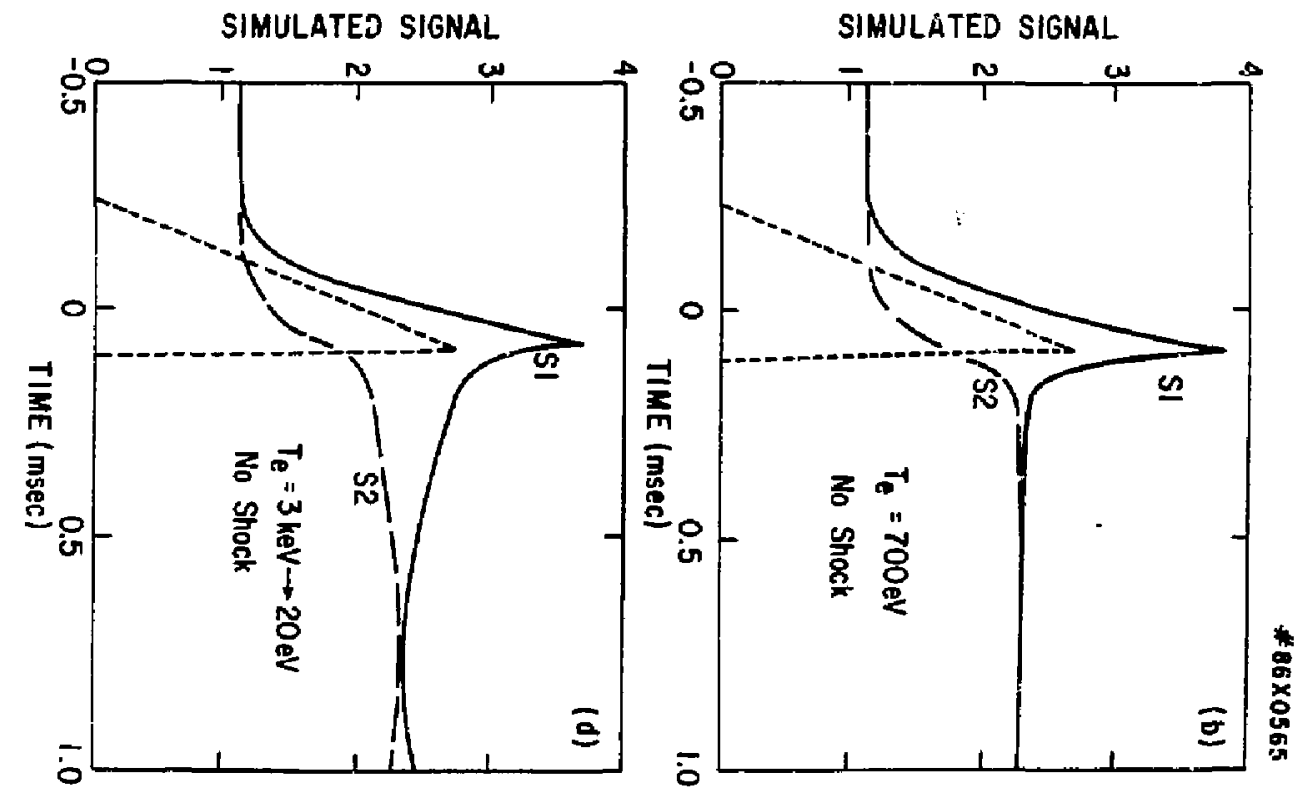




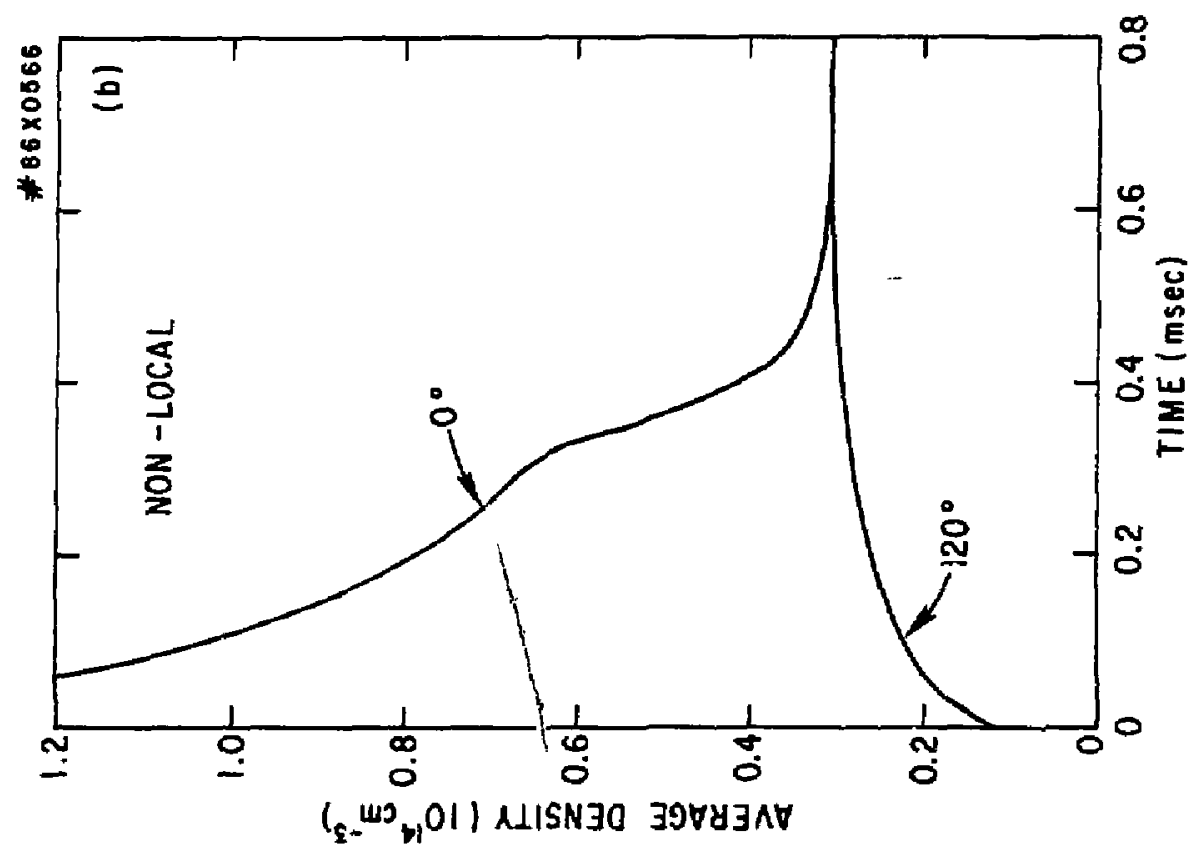

E)

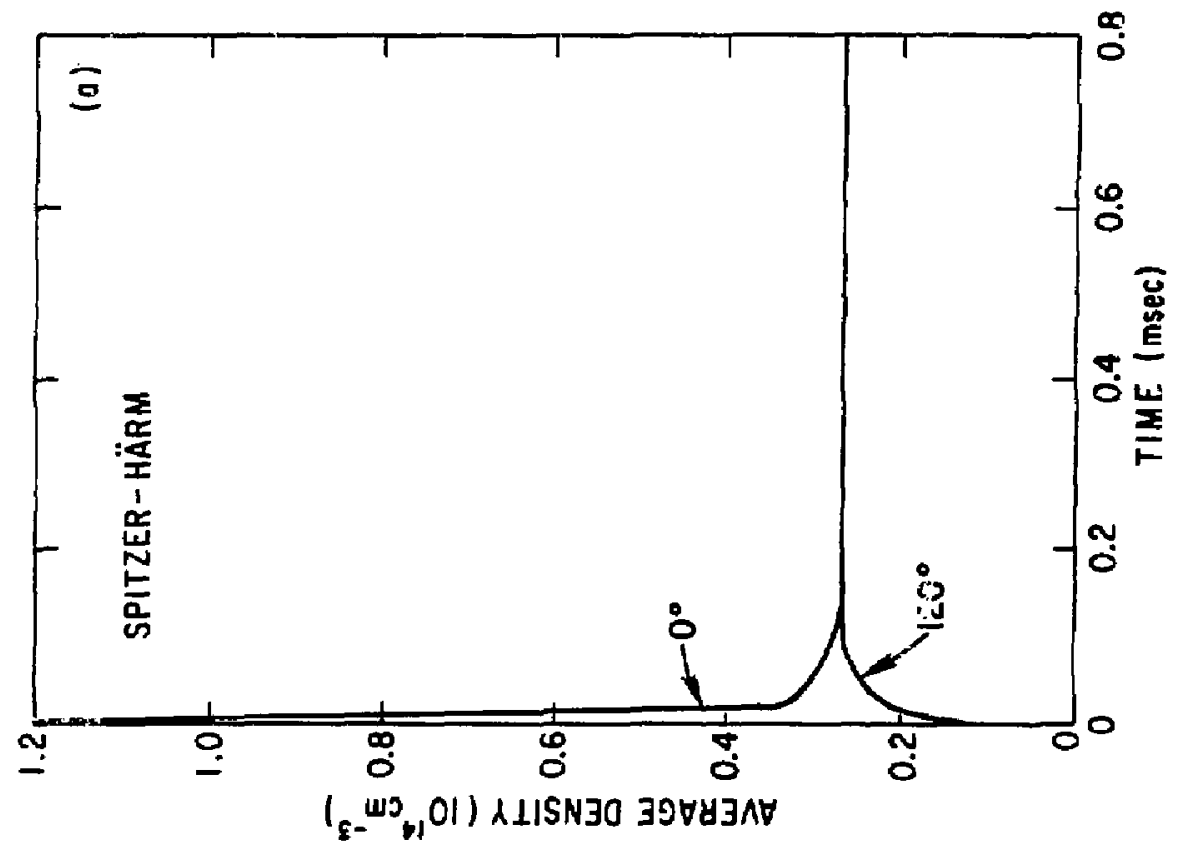


Plasma Res Lab, Austra Hat'l UnIv, AustaliA Or. Frank J. Peolonl, Univ of Wollongong, AUSTRALIA Prot. I.R. Jones, Fllnders Unlv., AUSTRALIA Prof, H.H. Erennan, UnIV SYdney, AUSTRALIA Prof, F. Cap, Inst Theo Dhys, AUSTRIA H. Goossans, Aagronnmlsch Instituut, BELGILA Prof. R. Bouclque, Laboratorilum voor Natuurkunde, BELGIUM Dr. D. Palumbo, Og XhI fuslon Prog. BelgiuH Ecole Royale Millitalre, Lab de Phys Plasmas, Belgium Dr. P.H. Sakanaka, InIv Estadual, BRRIL

LIb. B Doc, DIV., Instituto de Pesqulsas Espacials, BRRIL Or. CR. Jemes, UnIV of Alberta, CANOA

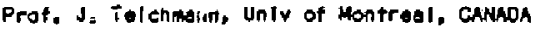
Dr. H, M. Sicarsgard, lnIV of Saskatchewan, CANen Prof. S.R. Sreanlvasan, University of Calgary, ChMaA Prcf. Tudor W. Johnston, INRS-Energle, CNWDA Or. Mannes Barnard, Uriv BrItlsh Columbla, CAMOA Or. M,P. Bschynsikt, Ma Tochnologles, Inc., CAMnDA CMalk RIver, NuCI Lab, CANLADA

Znengeu LI, 5N Inst Physles, CHINA

Library, Tsing Hua University, CHINA

Llorarlan, Institute of Physles, CHIMA Inst Plasme Phys, Acsdante SInlea, CHIMA C-. Poter Lukac, Komenskaho Univ, CECHOSLOVAKIA The LIErarfian, Culhew Laboratory, ENGLAND Prof. Schareman, Observatolre do HICo, FRANCE J. Radet, CEN-BPS, FRANCE JET Roading Room, JET Joint Undertaking, ENG!AND AH Dupas Librory, M Dupes LIbrary, FRANCE Or. Tom Mual, Academy gl bllographic, HONG KONG Preprint Library, Cunt Res Inst Phys, HungaRy Dr. R.K. Chhajlant, VIkram Untr. INOIA Or. B. Dasgupta, Saha Inst, INDIA Or. P. Kaw, Physlcal Research Lab, IMDIA Or. Phill lo Rosenau, Israel Inst Tech, ISRAEL Prof. S. Cuperman, Tol AvIv UnIversity, ISRAEL Prof. G. Rostagnt, Untr DI Padova, 1TALY LIbrarian, Int'l cte Theo Phys, ITALy miss Cleila de Palo, Aseoc ELRATOM-EMEA, ITALY BIbIlotoca, del CWA ELRATOH, ITALY Dr. H. Yomato, TolhI ba Res \& Dev, JAPAN DIrec. Dapt, Lg. Tokasak Dov, JAERI, JAPAH Prot, Hobuyuk! Inowe, Unfuersity of Tokyo, JAPAN Research Into Center, Nagoye University, JAPAN Prof. KyoJI Nishlkawa, Unlv of HIroshlm, JAPAK Prof. Sljeru Morl, HERt, JAPAN

Prot, 5. Tanake, Kyoto University, JAPAN Llbrary, Kyoto UnIversity, JAPAN Prof. I ehl ro Kawakial, HIthon UnIY, JAPAY Prof. Satoant Itoh, Kyushu UnIvarsity, JAPAN Dr, 0.1. Chol, Adv. Inst Sel a Tech, kores Tech Into OIvIsIon, KHERI, KOREA
Qlollorheak, fom-1nst voor Plasma, NEThERLANDS Prof. B.S. Llley, Univarsity of Walkato, NEW ZEALAND Prof. J.A.C. Cabral, Inst Superior Toen, PORTJGAL Dr. Oetavian Potrus, ALI CLZA Unlvorsity, ROMANIA Prot, M,A. Hellbarg, Unlyarsity of Natal, 50 AFRICA Dr. Jahan de VIlllers, Plosmo Physles, Nucor, SO AFkicA Fusion DiY. Llorary, JEN, SPAIN

Prof. Hans wilhalmson, Chalmars UnIr Tech, SWEDEN Dr. Lennart stenflo, UnTversity of UAEA, SWEDEN Llbrary, koyal Inst Toch, SHEDEN

Centro de Recherchesen, Ecole Pclytech Fed, Sw!tzerLanJ Dr. Y.T. Tolok, Kharkay Phys Tech Ins, USSR

Dr. D.D. Ryutov, SI berlan Acas SeF, USSR Dr. G.A. Ellsoov, Kurchatov Instituts, USSR Dr. Y.A. Glukhikh, Inst Electro-Physleal, USSa Institute Gen. Physics, USSR

Prot. T.J.M. Boyd, Univ Coltege N Wales, MaLES Or. K. Senlndier, Ruir Unlrorsitat, W. GERMany ASDEX Reading Rih, IPP/Max-Planck-Institut fur PlasmophysIK, F.R.G.

Nuclear Res Estob, Jullich Ltd, W, GERMANY Llbrarlan, Max-Planek Institut, W. GERMANY Bibllothat, Inst Plasmaforschung, W. GERMANY Piof. R.K. Janoy, Inst Phys, Yugoslayia 